\title{
Aplicación de DInSAR a los estudios de subsidencia en el Valle de Mexicali
}

\author{
Olga Sarychikhina ${ }^{1 *}$, Ewa Glowacka ${ }^{1}$, Francisco Suárez Vidal ${ }^{1}$, Robert \\ Mellors ${ }^{2}$ y Jorge Ramírez Hernández ${ }^{3}$ \\ ${ }^{1}$ División de Ciencias de la Tierra, CICESE, Carret. Ensenada-Tijuana No. 3918, Zona Playitas, Ensenada, \\ 22860, B.C., México \\ ${ }^{2}$ Department of Geological Sciences, San Diego State University, 5500 Campanile Drive, San Diego, CA, \\ 92182, USA. \\ ${ }^{3}$ Instituto de Ingeniería, UABC, Blvd. Benito Juárez y calle de la Normal s/n, Col. Insurgentes Este, Mexicali, \\ 21280, B.C., México \\ *osarytch@cicese.mx
}

\begin{abstract}
Resumen
Es bien conocido que la extracción en los campos geotérmicos está frecuentemente acompañada por subsidencia, que alcanza docenas de centímetros por año. La subsidencia causada por la extracción de fluidos geotermales en el campo geotérmico Cerro Prieto, localizado en el Valle de Mexicali, alcanza una tasa de $18 \mathrm{~cm} /$ año y afecta la infraestructura de carreteras, vías de tren, canales de irrigación y terrenos de los poblados y campos agrícolas. Se usaron datos de Interferometría Diferencial de Radar de Apertura Sintética (DInSAR, por sus siglas en inglés) y se compararon con datos históricos de nivelación de precisión, observaciones continuas de instrumentos geotécnicos instalados en la zona y resultados de reconocimiento geotectónico del área de estudio para definir la zona, fronteras y tasa de subsidencia. El resultado del estudio permite distinguir que el área de subsidencia está limitada por las fallas: Imperial, Cerro Prieto, Saltillo y Morelia, zona conocida también como cuenca Cerro Prieto, siendo una zona de subsidencia más grande que el área del campo geotérmico Cerro Prieto. La comparación de las tasas de subsidencia obtenidas para 1994-1997 por nivelación y para 2006-2007 por el método de DInSAR permite determinar la dinámica del proceso de subsidencia en el área de estudio y relacionarla con los cambios en extracción de fluido en el campo geotérmico Cerro Prieto.
\end{abstract}

Palabras clave: DInSAR, subsidencia, Valle de Mexicali, campo geotérmico, Cerro Prieto, extracción de fluidos.

\begin{abstract}
It is widely known that geothermal fluid extraction is frequently accompanied by ground subsidence which reaches dozens of centimeters per year. In the Cerro Prieto geothermal field, located in the Mexicali Valley, the subsidence caused by geothermal fluid extraction reaches the rate of $18 \mathrm{~cm} / y \mathrm{r}$ and is causing damage to infrastructure like roads, railroad tracks, irrigation channels, and agricultural fields. In this paper, Differential Interferometry of Synthetic Aperture Radar (DInSAR) data were used and compared with historic precise leveling data, continuous observation of geotechnical instruments installed in the area, and data from geotectonic field mapping to determine the area, limits and rate of subsidence. The results of this study suggest that the area of subsidence is limited by faults: Imperial, Cerro Prieto, Saltillo and Morelia; area also known as Cerro Prieto basin, so the area of subsidence is larger than the area of Cerro Prieto geothermal field. The comparison of subsidence rates obtained by leveling for 1994-1997 and DInSAR method for 2006-2007 allow to determine the subsidence dynamic and relate it with changes in geothermal fluid extraction rate in the Cerro Prieto geothermal field.
\end{abstract}

Key words: DInSAR, subsidence, Mexicali Valley, geothermal field, Cerro Prieto, fluid extraction. 


\section{Introducción}

La técnica de Interferometría Diferencial de Radar de Apertura Sintética (Differential Interferometry of Synthetic Aperture Radar), DInSAR, es conocida desde los años noventa y ha sido aplicada al registro y análisis de deformaciones relacionadas con sismos (Massonnet et al., 1993; Stramondo et al., 1999; Fielding et al., 2005), volcanes activos (Massonnet et al., 1995; Sigmundsson et al., 1999; Amelung et al., 2000), glaciares (Goldstein et al., 1993; Kwok y Fahnestock, 1996), deslizamientos (Carnec et al., 1996) y hundimientos causados por extracción de material en minas (Carnec y Delacourt, 2000; Wegmüller et al., 2004) o extracción de fluidos. La técnica de DInSAR se ha aplicado tanto para análisis de efectos de extracción de agua en acuíferos someros (e.g. Bawden et al., 2001, Hoffmann et al., 2001) como profundos, tal es el caso de algunos campos geotérmicos del mundo (Massonet et al., 1997; Fialko y Simons, 2000).

Los primeros resultados del análisis de DInSAR en el Valle de Mexicali ya existen en la literatura internacional. Carnec y Fabriol (1999) y Hanssen (2001) interpretaron algunas imágenes de Radar de Apertura Sintética (Synthetic Aperture Radar), SAR, de satélites ERS 1/2 adquiridas en 1993-1997 y 1995-1997, respectivamente (Tabla 1). Sus resultados mostraron que el área de campo geotérmico Cerro Prieto se hunde debido a la extracción de fluido geotérmico. La comparación de los datos de DInSAR con los datos de nivelación de 1994-1997 mostró que la tasa y el patrón de subsidencia estimados por ambas técnicas para el área de campo geotérmico Cerro Prieto es aproximadamente igual, con máximo hundimiento de $\sim 12 \mathrm{~cm} / \mathrm{año.} \mathrm{Sin}$ embargo, no les fue posible definir la extensión de la zona de hundimiento debido a la baja calidad (baja coherencia) de los datos de DInSAR en las zonas alrededor del campo causada por la presencia de vegetación en los campos agrícolas. Los resultados obtenidos por estos trabajos abarcaron aproximadamente la mitad de zona afectada por subsidencia y determinada usando los datos de nivelación (Figura 1). En Sarychikhina et al. (2007) se usaron las imágenes de SAR avanzado (Advanced SAR), ASAR, de satélite ENVISAT adquiridas en 2003-2005 (Tabla 1) para evaluar las capacidades y limitaciones de la técnica de DInSAR para el estudio de la subsidencia en el Valle de Mexicali. Se diagnosticaron algunos cambios en el patrón de subsidencia comparando con los datos de nivelación de temporadas previas a las fechas de adquisición de las imágenes analizadas. Sarychikhina et al. (2009) aplicaron la técnica de DInSAR para el estudio de la deformación cosísmica causada por un sismo de magnitud moderada $(\mathrm{Mw}=5.4)$ (Tabla 1). Glowacka et al. (2010) utilizaron un par interferométrico (Tabla 1) para apoyar las conclusiones acerca de la dinámica del proceso de hundimiento hechas con base en el registro de un extensómetro vertical y datos de evolución de producción en el campo geotérmico Cerro Prieto.
Actualmente, CICESE continúa con la detección y el monitoreo de la deformación del terreno en el Valle de Mexicali usando la técnica de DInSAR. En este trabajo los datos de DInSAR se analizan junto con los datos de instrumentos geotécnicos instalados en la zona y los resultados de reconocimiento geotectónico del área de estudio para definir la zona, fronteras y tasa de subsidencia en el periodo analizado. La comparación de la tasa de subsidencia obtenida con los datos históricos de nivelación de precisión permite confirmar los resultados acerca de la relación de la dinámica del proceso de subsidencia y la evolución de la producción en el campo geotérmico Cerro Prieto sugerida por los trabajos previos (Sarychikhina et al., 2007; Glowacka et al., 2010).

\section{La técnica de DInSAR}

En los párrafos siguientes se presenta una breve introducción a la teoría básica requerida para entender la técnica de DInSAR con base en los libros de Henderson y Lewis (1998) y Hanssen (2001). Los posibles errores y limitaciones de la técnica también se discuten.

Los sistemas de Radar de Apertura Sintética, SAR, son sistemas de radares coherentes que generan imágenes de alta resolución. Una apertura sintética o antena virtual consiste en un extenso arreglo de señales de radar sucesivas y coherentes que son transmitidas y recibidas por una pequeña antena que se mueve a lo largo de un determinado recorrido de vuelo u órbita. El procesamiento de la señal usa las amplitudes y fases de la señal recibida sobre pulsos sucesivos para crear una imagen. Las imágenes SAR expresan la distribución espacial de la amplitud y la fase de la señal retornada por el terreno y/o los objetos presentes en la escena en el área barrida por el satélite. La amplitud está directamente relacionada con las propiedades dieléctricas (reflectividad) del terreno. Por otra parte, la fase de la señal está vinculada con la distancia entre el sensor (satélite) y el suelo para cada pixel. Además, la señal reflejada puede sufrir un posible desfase debido a reflectividad del terreno, a la propagación de la señal a través de la atmósfera y al ruido.

La interferometría SAR, InSAR, es una técnica geodésica establecida, basada en la combinación de dos imágenes SAR de la misma escena adquiridas desde puntos ligeramente diferentes. Esta combinación da como resultado una nueva imagen conocida como interferograma. La toma de imágenes puede ser simultánea, tomándose las imágenes mediante dos antenas ligeramente separadas o de forma secuencial. En este último caso, la primera imagen es la imagen de referencia llamada master, mientras que la segunda (adquirida con fecha posterior a la primera) es llamada imagen slave. Suponiendo que las fases de reflectividad del terreno y de retraso atmosférico son las mismas en ambas imágenes, y que el ruido en ambas imágenes puede ser omitido, la fase del interferograma (fase 
Tabla 1. Parámetros de pares interferométricos usados en este trabajo y en los trabajos previos acerca las deformación (antropogénica y sísmica) del terreno en el Valle de Mexicali. A y D indica el paso ascendente (paso \#306, escena 639) y descendente (paso \#84, escena 2961), respectivamente. * Los valores de la línea de base perpendicular $\left(B_{\perp}\right)$ no han sido publicados. En la tabla, se presentan valores de $B_{\perp}$ obtenidos usando el programa DESCW99 de Agencia Espacial Europea (European Space Agency), ESA.

\begin{tabular}{|c|c|c|c|c|c|}
\hline \multirow{2}{*}{ Satélite } & Imagen master & Imagen slave & \multirow{2}{*}{$\mathrm{B}_{\perp}(\mathrm{m})$} & \multirow{2}{*}{$\mathrm{B}_{\text {temp }}$ (días) } & \multirow{2}{*}{ Procesado por: } \\
\hline & (año/mes/día) & (año/mes/día) & & & \\
\hline ERS $1 / 2(D)$ & $1993 / 07 / 01$ & $1997 / 06 / 29$ & 219 & 1459 & \multirow{10}{*}{ Carnec y Fabriol (1999) } \\
\hline ERS 1 (D) & $1993 / 07 / 01$ & $1996 / 03 / 30$ & 166 & 1003 & \\
\hline ERS 1 (D) & $1993 / 09 / 09$ & $1995 / 12 / 16$ & 693 & 828 & \\
\hline ERS 1 (D) & $1993 / 09 / 09$ & $1996 / 05 / 04$ & 64 & 968 & \\
\hline ERS $1 / 2(D)$ & $1993 / 09 / 09$ & $1996 / 10 / 27$ & 41 & 1144 & \\
\hline ERS 2 (D) & $1995 / 12 / 16$ & $1996 / 05 / 04$ & 60 & 140 & \\
\hline ERS $1 / 2(D)$ & $1996 / 03 / 30$ & $1997 / 06 / 29$ & 95 & 456 & \\
\hline ERS $1 / 2(D)$ & $1996 / 05 / 04$ & $1996 / 10 / 27$ & 116 & 176 & \\
\hline ERS 2 (D) & $1997 / 05 / 25$ & $1997 / 06 / 29$ & 40 & 35 & \\
\hline ERS 2 (D) & $1997 / 06 / 29$ & $1997 / 08 / 03$ & 47 & 35 & \\
\hline ERS 2 (D) & $1997 / 05 / 25$ & $1997 / 08 / 03$ & 261 & 70 & $\begin{array}{c}\text { Carnec y Fabriol (1999); } \\
\text { Hanssen (2001) }\end{array}$ \\
\hline ERS $1 / 2(D)$ & $1995 / 05 / 20$ & $1995 / 11 / 12$ & $133^{*}$ & 176 & \multirow{7}{*}{ Hanssen (2001) } \\
\hline ERS 1 (D) & $1996 / 01 / 20$ & $1995 / 05 / 20$ & $30^{*}$ & -245 & \\
\hline ERS $1 / 2(D)$ & $1996 / 01 / 20$ & $1997 / 01 / 05$ & $32 *$ & 351 & \\
\hline ERS $1 / 2(D)$ & $1996 / 01 / 20$ & $1997 / 05 / 25$ & $66^{*}$ & 491 & \\
\hline ERS 2 (D) & $1995 / 11 / 12$ & $1996 / 01 / 21$ & $33^{*}$ & 70 & \\
\hline ERS 2 (D) & $1997 / 01 / 05$ & $1997 / 03 / 16$ & $81^{*}$ & 70 & \\
\hline ERS 2 (D) & $1997 / 03 / 16$ & $1997 / 05 / 25$ & $47 *$ & 70 & \\
\hline ENVISAT (A) & $2003 / 12 / 16$ & $2004 / 02 / 24$ & 157 & 70 & \multirow{4}{*}{ Sarychikhina et al. (2007) } \\
\hline ENVISAT (D) & $2004 / 12 / 19$ & $2005 / 01 / 23$ & 77 & 35 & \\
\hline ENVISAT (D) & $2005 / 05 / 08$ & $2005 / 10 / 30$ & 160 & 175 & \\
\hline ENVISAT (D) & $2003 / 10 / 26$ & $2004 / 10 / 10$ & 147 & 350 & \\
\hline ENVISAT (D) & $2005 / 12 / 04$ & $2006 / 02 / 12$ & 300 & 70 & $\begin{array}{c}\text { Sarychikhina et al. (2009) } \\
\text { Glowacka et al. (2010) }\end{array}$ \\
\hline ENVISAT (A) & $2006 / 05 / 09$ & $2006 / 09 / 26$ & 307 & 140 & \multirow{5}{*}{ Sarychikhina et al. (2009) } \\
\hline ENVISAT (A) & $2006 / 04 / 04$ & $2006 / 09 / 26$ & 162 & 175 & \\
\hline ENVISAT (A) & $2006 / 04 / 04$ & $2006 / 10 / 31$ & 152.7 & 210 & \\
\hline ENVISAT (D) & $2006 / 02 / 12$ & $2006 / 11 / 19$ & 178.6 & 280 & \\
\hline ENVISAT (D) & $2006 / 03 / 19$ & $2006 / 12 / 24$ & 123.7 & 280 & \\
\hline ENVISAT (A) & $2006 / 12 / 05$ & $2007 / 03 / 20$ & 41 & 105 & \multirow{2}{*}{ Este trabajo } \\
\hline ENVISAT (D) & $2006 / 12 / 24$ & $2007 / 03 / 04$ & 55 & 70 & \\
\hline
\end{tabular}

interferométrica, $\phi$ ) será calculada restando las fases de las dos imágenes SAR:

$\phi=\phi_{M}-\phi_{S}=\frac{4 \pi\left(R_{M}-R_{S}\right)}{\lambda}=\frac{4 \pi \Delta R}{\lambda}$

donde $\phi_{M}$ y $\phi_{S}$ son las fases de las imágenes, $R_{M}$ y $R_{S}$ son las distancias entre el sensor y el punto-dispersor en el terreno y $\lambda$ es la longitud de onda usada.

La ecuación (1) sugiere que en las condiciones previa- mente mencionadas, la fase interferométrica es proporcional a la diferencia de caminos recorridos por la señal durante dos adquisiciones. Debido a la diferencia en la geometría de las adquisiciones, la diferencia en caminos recorridos por la señal es la suma de varias contribuciones producidas por una superficie de referencia sin relieve $\left(\Delta R_{e}\right.$, curved Earth), topografía $\left(\Delta R_{t}\right)$, y la deformación $\left(\Delta R_{d}\right)$ :

$\phi=\frac{4 \pi}{\lambda}\left(\Delta R_{e}+\Delta R_{t}+\Delta R_{d}\right)$ 


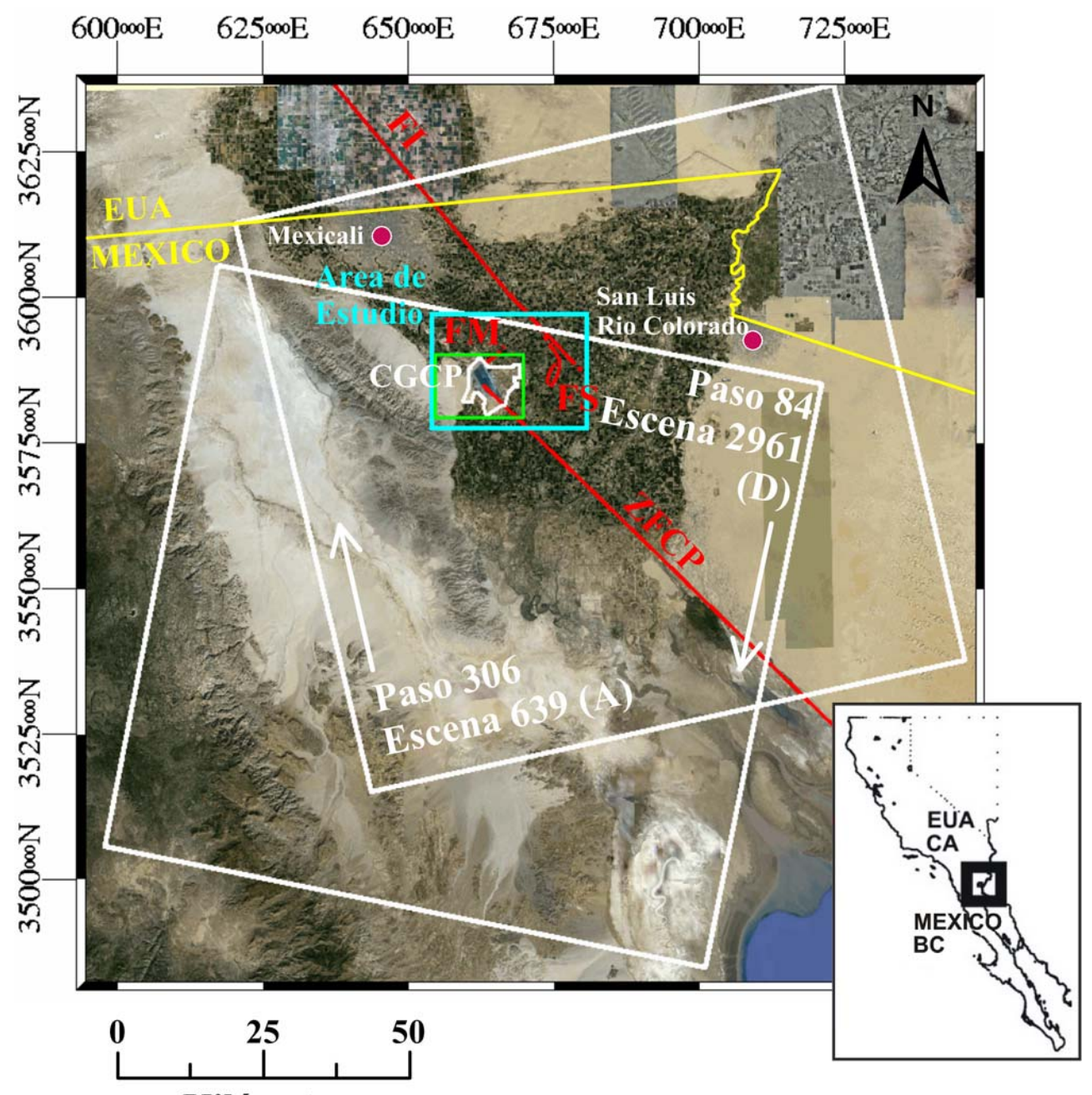

Kilómetros

Figura 1. Escenas de imágenes de ENVISAT y la zona de estudio. El rectángulo azul celeste delimita el área de estudio. Los rectángulos blancos delimitan las escenas de imágenes de ENVISAT. A y D indican el paso ascendente y descendente, respectivamente. Las flechas blancas indican la dirección de vuelo para cada paso. El Campo Geotérmico Cerro Prieto (CGCP) está delimitado por una línea blanca. El rectángulo verde delimita la zona de análisis de subsidencia realizado por Carnec y Fabriol (1999) y Hanssen (2001) usando la técnica de DInSAR. Se muestran las principales fallas activas de la zona. $\mathrm{ZFCP}=$ Falla Cerro Prieto, FI = Falla Imperial, FS = Falla Saltillo, FM = Falla Morelia.

La técnica de InSAR diferencial clásica, DInSAR, trata de eliminar las componentes conocidas de la ecuación (2) para obtener la fase relacionada con las deformaciones del terreno. La contribución de una superficie de referencia (también conocida como contribución orbital) puede ser estimada usando órbitas precisas. La contribución topográfica puede ser simulada a partir de un modelo digital de elevación externo o estimada de un interferograma independiente y después restada del interferograma original.

Debido al carácter cíclico de la fase, la fase interferométrica se obtiene con valores comprendidos entre $-\pi$ y $\pi$ (o entre 0 y $2 \pi$ ), es decir, la fase interferométrica tiene módulo $2 \pi$, y se le conoce como fase enrollada. El procedimiento que se utiliza para recuperar la fase original de la señal se llama desenrollo de fase (phase unwrapping), y es un paso importante en el procesamiento interferométrico. La sensibilidad de la fase interferométrica para detectar la deformación es muy alta. Cada franja equivale aproximadamente a una diferencia de distancia (deformación) de $\lambda / 2$ en la línea de la observación del radar (Line Of Sight), LOS.

La calidad de los datos de deformación del terreno obtenidos usando la técnica de DInSAR depende de la calidad de la fase interferométrica diferencial. El parámetro usado para evaluar la calidad de fase se denomina coherencia interferométrica $(\gamma)$, y puede ser interpretada como una herramienta útil para medir la semejanza entre las dos imágenes SAR. La coherencia interferométrica para dos imágenes SAR complejas $g_{M}$ (imágen master) y $g_{S}$ (imágen slave) se define como:

$\gamma=\left|\frac{\sum g_{M} g_{S}^{*}}{\sqrt{\sum\left|g_{M}(x, y)\right|^{2} \sum\left|g_{S}(x, y)\right|^{2}}}\right|$ 
donde $\mathrm{g}_{\mathrm{s}}^{*}$ es el complejo conjugado de la imágen slave.

La coherencia se encuentra definida entre los valores 0 y 1 . Si la coherencia es igual a cero, significa que la escena está completamente decorrelacionada y así el interferograma es ruido y no está relacionado con la deformación. En el otro extremo, una coherencia cercana a uno corresponde a un interferograma libre de ruido a partir del cual un mapa de deformación de alta calidad puede ser generado.

Las fuentes de decorrelación (o degradación de coherencia) son la decorrelación temporal y decorrelación espacial.

La decorrelación temporal se debe a las variaciones de reflectividad de los puntos de la imagen que pueden ser causadas por: lluvia, viento sobre la vegetación, crecimiento de la misma, arado de campos, etc.

La decorrelación espacial se debe a cambios en la geometría de adquisición de las imágenes. La degradación de correlación aumenta mientras aumenta la distancia que hay entre los satélites en el momento de realizar las adquisiciones, también conocida como línea de base. La componente de la línea de base perpendicular a la dirección de observación $B_{\perp}$ tiene mayor influencia en el grado de decorrelación espacial.

Los errores orbitales y topográficos son los otros factores que afectan la fase interferométrica diferencial y pueden crear confusión en su interpretación.

La componente atmosférica representa otra importante fuente de error. Las imágenes al no ser adquiridas al mismo tiempo pueden haber sido tomadas en condiciones atmosféricas diferentes, por lo que varía el camino eléctrico recorrido por la señal. Los mapas de coherencia no pueden medir este ruido. Teniendo disponible sólo un par de imágenes SAR, la identificación de artefactos atmosféricos y su cuantificación es una tarea imposible sin usar la información externa (GPS, MERIS, MeteoSat). En algunos casos los artefactos atmosféricos pueden ser ignorados (alta tasa de deformación o patrón espacial especifico). En casos donde varias imágenes están disponibles, la comparación de múltiples interferogramas puede ayudar a identificar las imágenes que son afectadas gravemente por perturbaciones atmosféricas. La suposición principal es que la fase de la deformación está altamente correlacionada entre los pares independientes de imágenes y los términos del error no lo están. Por lo tanto, la combinación de múltiples interferogramas, también puede ayudar a reducir la influencia de los artefactos atmosféricos.

\section{Subsidencia en el Valle de Mexicali}

El Valle de Mexicali está ubicado en la parte sur de la Depresión de Salton (Salton Trough), en la frontera entre las placas de Norteamérica y del Pacífico, en la parte sur del sistema de falla de San Andrés (Figura 1). El Valle está caracterizado por alta sismicidad, tectonismo activo, procesos hidrotermales y volcanismo reciente. En 1973 se inició la extracción de fluido en el campo geotérmico
Cerro Prieto de una profundidad entre 1500 y 3000 metros, y en 1989 se inició la inyección de salmuera al subsuelo profundo. Estos procesos han venido influyendo en el estado de esfuerzos, deformación y sismicidad de la zona. La subsidencia antropogénica causada por extracción profunda de fluidos en el campo geotérmico Cerro Prieto y rupturas relacionadas, están afectando la infraestructura ingenieril y social en la vecindad del campo causando daños a caminos, vías de tren y canales de irrigación, lo que incrementa los peligros naturales en esta zona, ya bastante vulnerable por su situación tectónica.

La sismicidad y deformación tectónica han sido estudiadas en el Valle de Mexicali durante muchos años (Lomnitz et al, 1970). Desde los años ochentas, Majer y McEvilly (1982), Glowacka y Nava (1996), Fabriol y Munguía (1997), Glowacka et al. (1999, 2005, 2010), Carnec y Fabriol (1999) y Hanssen (2001) han relacionado sismicidad y/o deformación con el proceso de extracción, y/o inyección de fluidos geotermales en el campo geotérmico Cerro Prieto. En el período de 1973 a 1997 la tasa de subsidencia aumentó después de cada aumento grande y sostenido de extracción (Glowacka et al., 1999). Con datos de la nivelación realizada en los años 1994 a 1997 (Figura 2) en el Valle de Mexicali, se hizo la modelación de la componente tectónica y antropogénica de la subsidencia (Sarychikhina, 2003, Glowacka et al., 2005) y se encontró que la subsidencia antropogénica es responsable del $94 \%$ al $96 \%$ de la subsidencia observada. La zona que presenta subsidencia de origen antropogénico coincide en posición, extensión y forma con la región de la subsidencia tectónica. Esto quiere decir que las características del proceso tectónico: localización y extensión de la zona de dispersión y las fallas de transformación asociadas, así como los mecanismos de sedimentación en la zona, han determinado la existencia del campo geotérmico y determinan ahora la región de extensión de la influencia de los procesos antropogénicos en éste.

Algunos reconocimientos geotectónicos del área de estudio han sido realizados (González et al., 1998; LiraHerrera, 2006; Suárez-Vidal et al., 2007, 2008; Glowacka et al., 2006, 2010) con el propósito de documentar rasgos de rompimiento, fracturas y desplazamientos (Figura 2) y comparar éstos con las fallas tectónicas conocidas en la región. Dichos reconocimientos geotectónicos sugieren que el área afectada por subsidencia está limitada a la zona comprendida entre las fallas Imperial, Saltillo, Cerro Prieto y Morelia, zona también conocida como cuenca Cerro Prieto (Suárez-Vidal et al., 2008).

Para estudiar la distribución espacial y temporal de las deformaciones de la corteza en el Valle de Mexicali, CICESE instaló una red de medidores de deformación. En 2006 la red incluyó 3 extensómetros, 6 inclinómetros, todos con medición continua; también incluyó un testigo 3D. Los datos de extensómetro vertical (EV, Geokon Vibrating Wire, modelo 4420) instalado en la falla Saltillo en 1996 y del testigo 3D (T-3D) instalado en la Zona de falla Cerro Prieto 


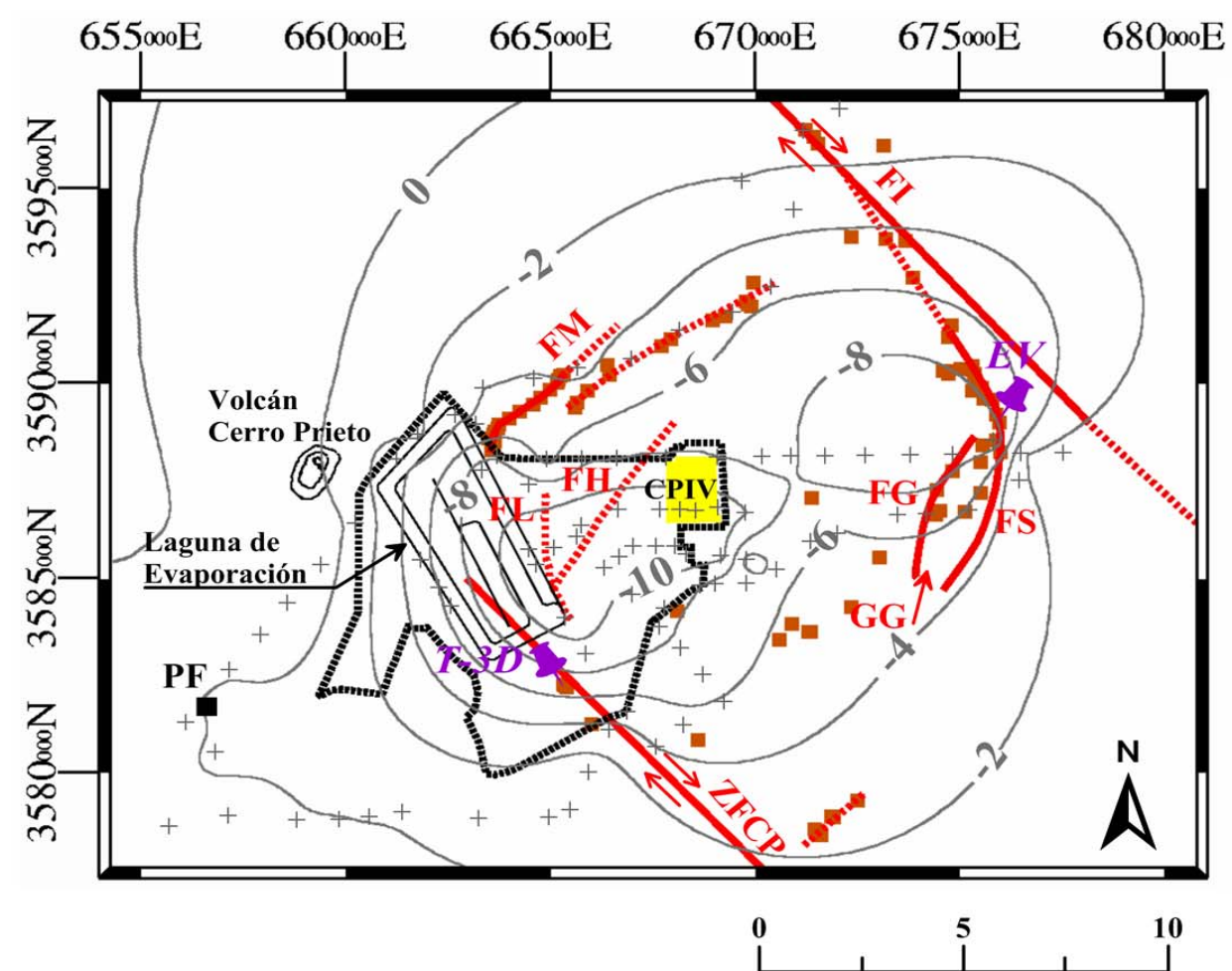

\section{LEYENDA:}

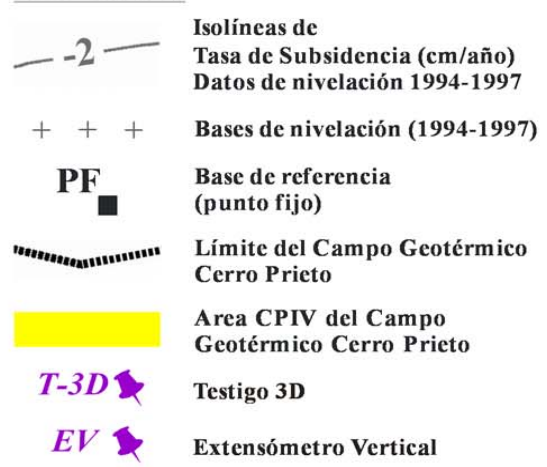

Kilómetros

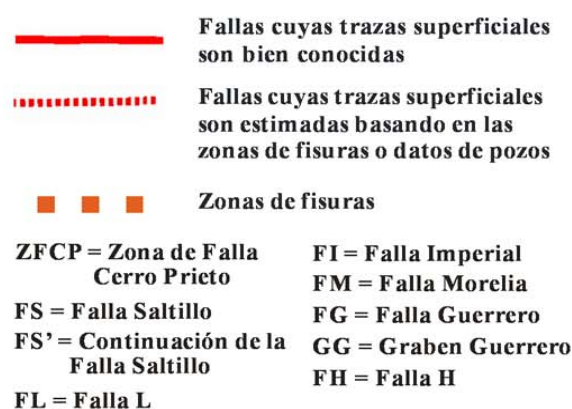

$\mathbf{F L}=$ Falla $\mathbf{L}$

Figura 2. Plan de área del estudio con los datos geodésicos (nivelación 1994-1997, Glowacka et al., 1999) y geológicos (González et al., 1998; LiraHerrera, 2006; Suárez-Vidal et al., 2007, 2008; Glowacka et al., 2006, 2010) sobrepuestos. La ubicación de instrumentos geotécnicos también se muestra.

en 2004 se utilizaron en este estudio. En las zonas donde se instalaron estos instrumentos geotécnicos, la falla Saltillo tiene un escarpe alto y bien definido, mientras que la falla Cerro Prieto se caracteriza por una amplia zona (Zona de falla Cerro Prieto, ZFCP) de escalonamientos dispersos y de baja amplitud.

El extensómetro (EV) mide el deslizamiento vertical en la falla registrando el desplazamiento entre 2 bases o monumentos situados en lados opuestos de ésta. El extensómetro EV tiene $\sim 3 \mathrm{~m}$ de largo y atraviesa la falla Saltillo en un plano perpendicular a ésta (Glowacka, 1996; Nava y Glowacka, 1999). El extensómetro tiene la resolución de $0.1 \mathrm{~mm}$, el rango de $70 \mathrm{~cm}$ y está tomando los datos cada 20 minutos. El diagrama de instalación de EV y su fotografía se presentan en la Figura $3 \mathrm{a}$.
El testigo 3D (T-3D, Witness o Deformation Gages), cuyo diseño y fotografía están presentados en la Figura 3b, mide 3 componentes del vector de deslizamiento en la falla (vertical, paralelo y perpendicular a la falla), registrando el desplazamiento relativo entre 2 bases o monumentos situados en lados opuestos de ésta. El testigo 3D no es un instrumento automatizado, y las mediciones se toman manualmente por el personal técnico durante las salidas al campo, 1 vez entre 1 y 3 meses.

Del análisis de datos del extensómetro vertical (EV) se puede observar que el deslizamiento en la falla Saltillo tenía velocidad vertical de 5-6 cm/año, en los años 90, y tiene velocidad vertical de $\sim 7.3 \mathrm{~cm} /$ año desde el año 2003 (Figura 4). El deslizamiento ocurre principalmente en eventos episódicos que duran 1-3 días. Dichos eventos 


\section{a. Extensómetro Vertical (EV), Vista Lateral}
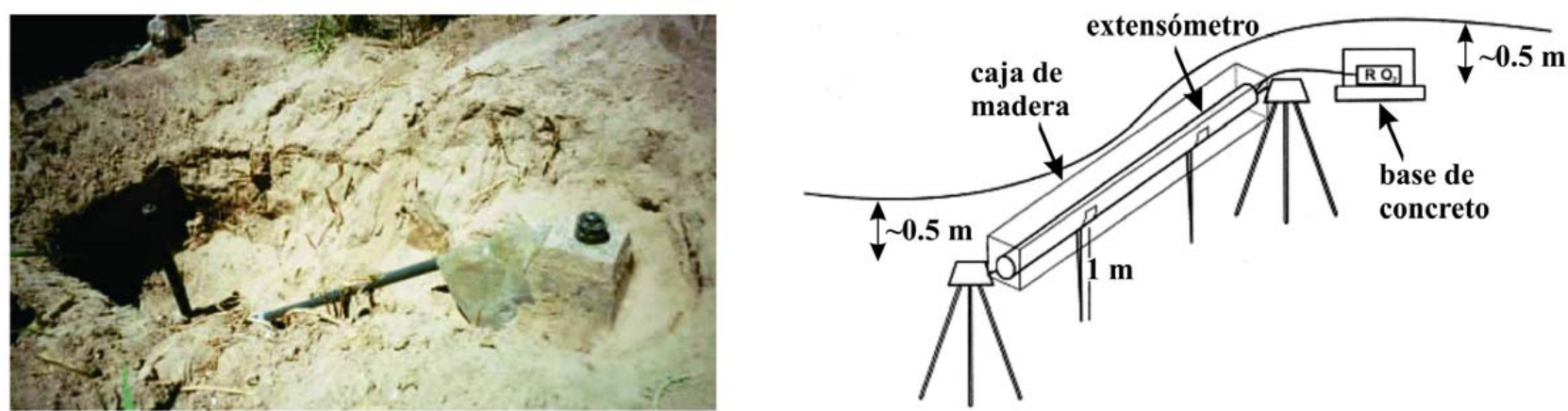

\section{b. Testigo 3-D, Vista Lateral}
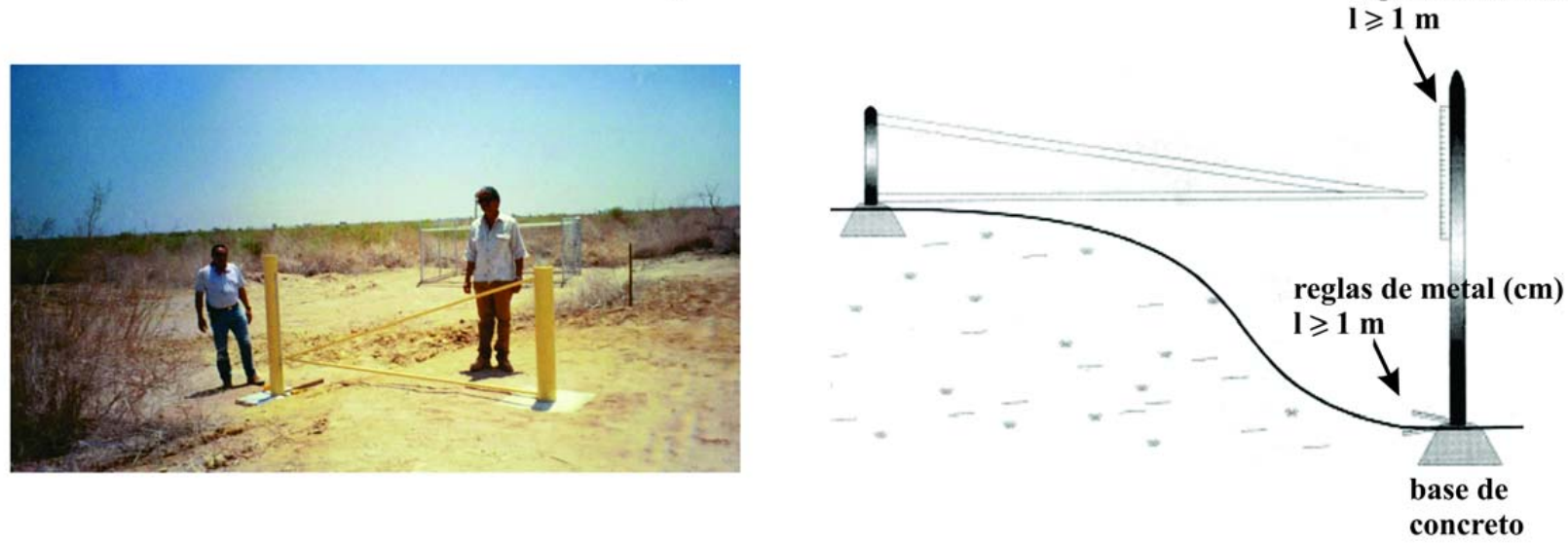

Figura 3. Fotografía y diagrama de instalación de los instrumentos geotécnicos: extensómetro vertical (EV) y testigo 3D (T-3D).

ocurren 1-3 veces al año y tienen la magnitud promedio de $20( \pm 10)$ mm (Nava y Glowacka, 1999; Glowacka et al., 1999; 2001).

El deslizamiento vertical en la falla Cerro Prieto, observado con Testigo 3D, es de $3.1 \mathrm{~cm} /$ año (Figura 4 ).

\section{Aplicación de DInSAR en el Valle de Mexicali}

Para la detección y el monitoreo de la deformación en el Valle de Mexicali, CICESE adquirió 27 imágenes SAR de paso descendente (\#84, escena 2961) y 16 imágenes de paso ascendente (\#306, escena 639) adquiridas en el periodo 2003-2007 por el satélite ENVISAT. La extensión espacial de las escenas mencionadas se presenta en Figura 1. Teóricamente, un gran número de pares interferométricos es posible. Sin embargo, como ha sido reportado por Sarychikhina et al. (2007), se observó una fuerte decorrelación espacial para los pares interferométricos con línea de base perpendicular $\left(B_{\perp}\right)$ mayor a los $400 \mathrm{~m}$. También se observó que, a pesar de la línea de base perpendicular corta, varios interferogramas presentaron un alto nivel de ruido en fase debido a la decorrelación temporal inducida por las variaciones de las propiedades dieléctricas del suelo entre las dos adquisiciones. Las zonas alrededor del campo geotérmico Cerro Prieto, con intensa vegetación debido a su uso agrícola, presentan importantes decorrelaciones de fase para los pares interferométricos que cubren el período mayor a tres meses $\left(B_{\text {temp }}>105\right.$ días $)$, mientras que para el área de campo geotérmico Cerro Prieto y la zona principalmente desértica al oeste del campo mantiene buena coherencia durante los períodos cubiertos por pares interferométricos más largos. Por lo tanto, el análisis de datos de DInSAR en el área de estudios se limita a los pares interferométricos de línea de base perpendicular corta y que cubren los periodos cortos. Esta restricción reduce sustancialmente el número de pares disponibles para el análisis.

Para la meta de este trabajo se seleccionaron dos pares interferométricos con fechas de adquisición de imágenes de 2006/12/05-2007/03/20 (ascendente), y 2006/12/242007/03/04 (descendente), con base en los parámetros de dichos pares interferométricos (Tabla 1) y la carencia de fuerte ruido y artefactos atmosféricos (según el análisis visual). 


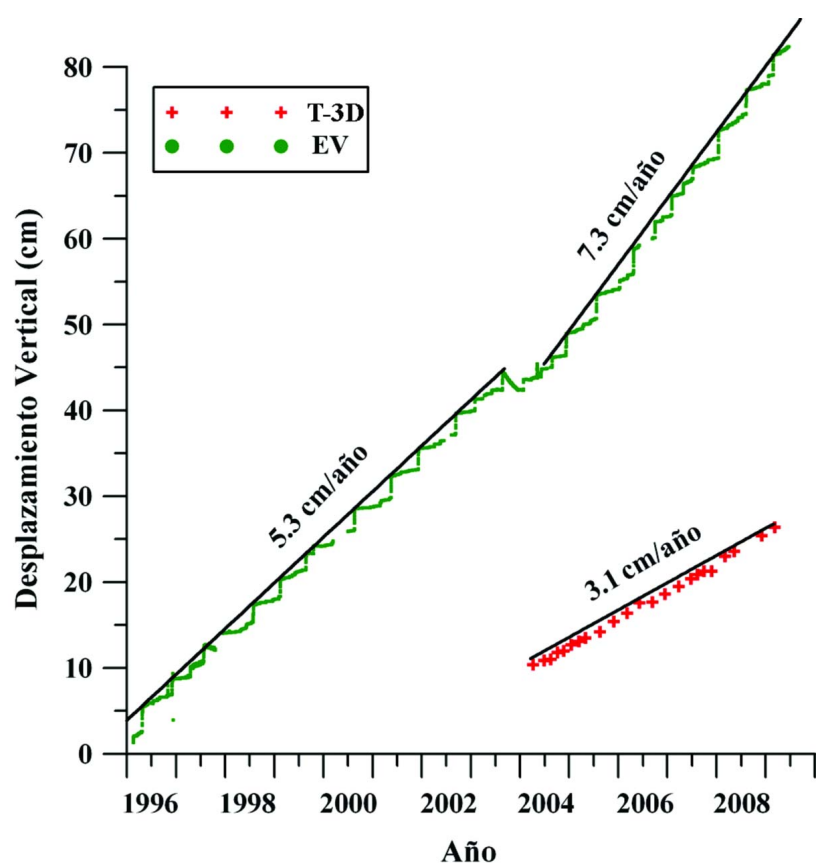

Figura 4. Desplazamiento vertical observado en extensómetro EV durante 1996-2008, y en Testigo 3D durante 2004-2008.

El procesamiento interferométrico, realizado usando el software DORIS versión 3.16 (Kampes, 2005; Kampes et al., 2003; Kampes y Usai, 1999), incluyó los siguientes pasos:

- Coregistro de las imágenes, que consiste en hacer corresponder los pixeles de una y otra imagen.

- Generación de interferograma (diferencia de fase). La fase del interferograma aparece enrollada en módulo de $2 \pi$. El factor de multi-look (o promediado de pixeles) usado es de $4 \times 20$ pixeles, lo que permite generar los productos interferométricos con tamaño de pixel de $\sim 100 \times 100 \mathrm{~m}^{2}$.

- Generación de imagen de coherencia.

- Corrección de interferograma por la geometría de adquisición de los datos: corrección "por Tierra plana" (elipsoide) y corrección por topografía, se realiza usando los datos de orbitas precisas de DEOS (Delft institute for Earth-Oriented Space research) y el modelo digital de elevación de SRTM3 (Shuttle Radar Topography Mission) con una resolución de 3 segundos de arco. El modelo digital de elevación de SRTM3 tiene un error vertical relativo promedio de $\sim 6 \mathrm{~m}$ (Muller y Backes, 2003). Por lo tanto, para los pares interferométricos escogidos, la componente de fase residual, debida a errores en el DEM utilizado, no es mayor a $\sim 0.1$ franjas, o $0.3 \mathrm{~cm}$. Por otra parte, como el Valle de Mexicali es topográficamente plano, esto ayuda a atenuar cualquier contribución de los artefactos relacionados con la topografía en los interferogramas, a excepción del área del volcán Cerro Prieto (Figura 5 y 6), donde también se puede esperar los artefactos atmosféricos relacionados con la topografía.
- Filtración de la fase interferométrica usando el filtro adaptante de Goldstein (Goldstein y Werner, 1998) y desenrollo de la fase interferométrica usando el software SNAPHU (Statistical-cost, Network-flow Algorithm for Phase Unwrapping) (Chen y Zebker, 2000, 2001) integrado como módulo a DORIS. El filtrado se realizó con el propósito de obtener los interferogramas con menor nivel de ruido (artefactos) y mejorar los resultados de desenrollado de la fase (unwrapping). Los parámetros del filtro fueron seleccionados iterativamente, logrando eliminar algunas diferencias entre imágenes que no se debían al proceso de deformación sino, más bien, se debían a los errores de desenrollado de la fase.

- Conversión de la fase desenrollada al desplazamiento LOS relativo y geocodificación de la información obteniendo como resultado el mapa de desplazamiento LOS relativo en coordenadas UTM (m) y datum NAD27.

Los resultados de coherencia y fase enrollada también fueron geocodificados y están presentados en Figura 5a, 5b y $5 \mathrm{c}, 5 \mathrm{~d}$, respectivamente. En la Figura 5 a y 5 b se puede observar muy alta coherencia dentro de los límites del campo geotérmico Cerro Prieto, excepto en el área de la laguna de evaporación, y al oeste del campo geotérmico. Una zona de baja coherencia se observa al este, sur y norte del campo geotérmico, y está relacionada con la presencia de actividad agrícola. En estas áreas podemos observar los errores del desenrollo relativamente altos en los mapas de desplazamiento presentados en la Figura 5e y 5f. Se nota coherencia ligeramente más alta en la Figura 5 b que se debe probablemente a una cobertura temporal menor del par interferométrico correspondiente. En la Figura 5c y 5d se puede observar que los dos interferogramas diferenciales independientes muestran franjas de cambio de fase bien definidas con el mismo patrón y localización geográfica. Por lo tanto, los cambios de fase no se deben a los efectos atmosféricos, sino que representan la deformación del terreno que ocurrió en el periodo cubierto por cada interferograma diferencial. El ángulo de observación de ENVISAT relativamente pequeño $\left(\sim 23^{\circ}\right)$, la similitud del patrón de las franjas en los interferogramas del paso descendente $\mathrm{y}$ ascendente y las evidencias de la deformación vertical obtenidas por las mediciones terrestres, incluyendo nivelación (Figura 2), sugieren que el incremento observado de la distancia entre el radar y superficie terrestre se debe principalmente al hundimiento del terreno, aunque éste no descarta la presencia de cierta componente horizontal.

Con base en la suposición de que el desplazamiento de la superficie está dominado por el movimiento vertical (ver el párrafo anterior), el desplazamiento LOS relativo, $\Delta R$, ha sido convertido al desplazamiento vertical relativo, $D_{V}$, usando la expresión:

$D_{V}=-\Delta R / \cos (\theta)=-\Delta R / 0.92$

donde $\theta$ es el ángulo de observación del radar. Debido a 
2006/12/05-2007/03/20 (A)

$B_{\perp}=41 \mathrm{~m}, B_{\text {temp }}=105$ días

a.

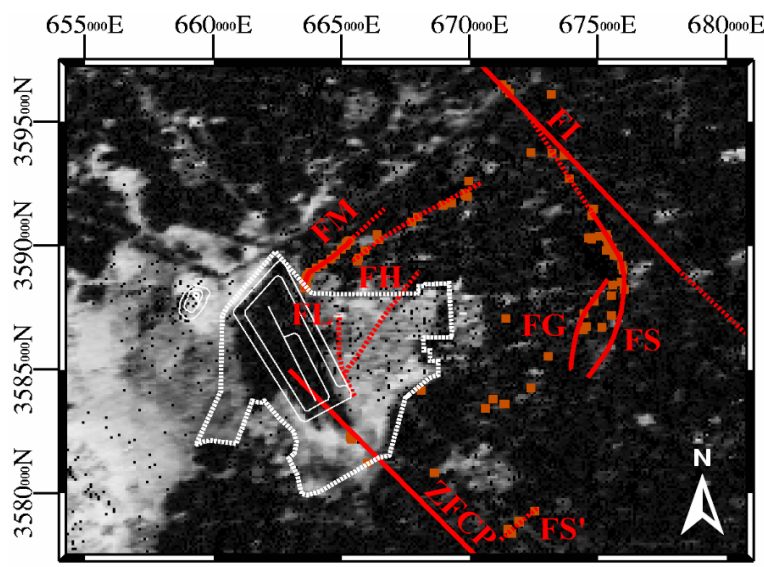

c.

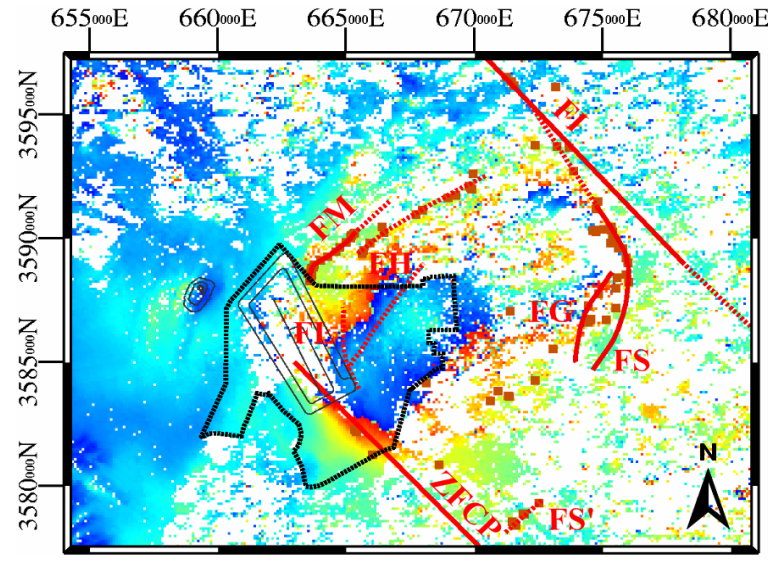

e.

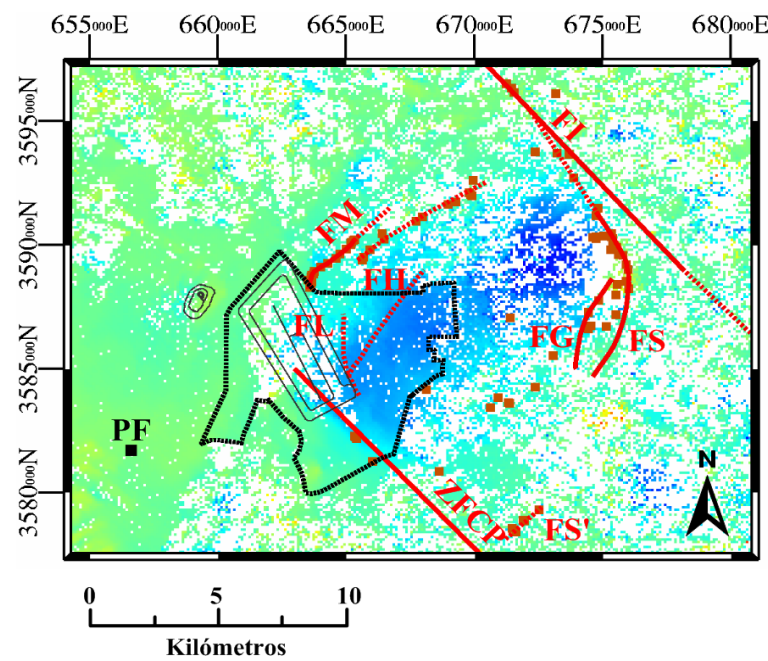

2006/12/24-2007/03/04 (D)

b.$$
B_{\perp}=-55 \mathrm{~m}, B_{\text {temp }}=70 \text { días }
$$

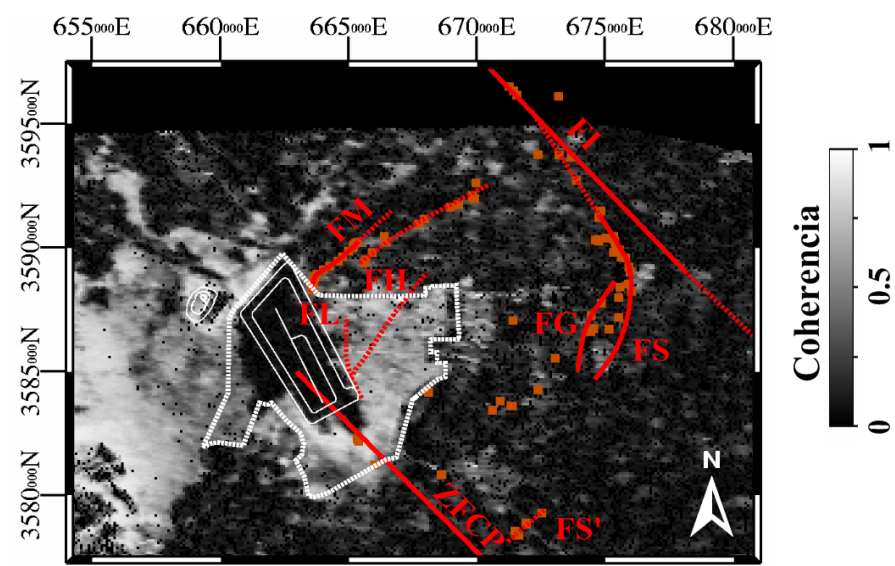

d.

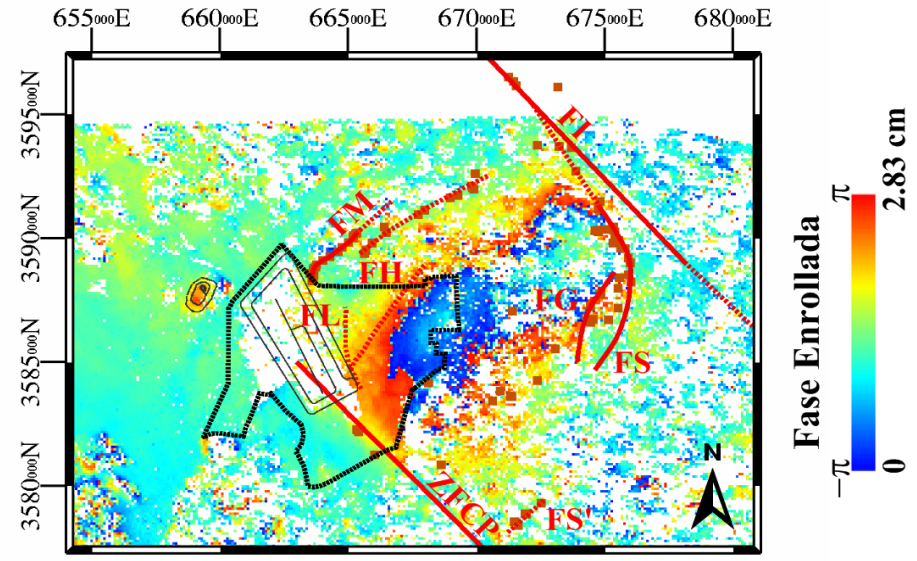

f.

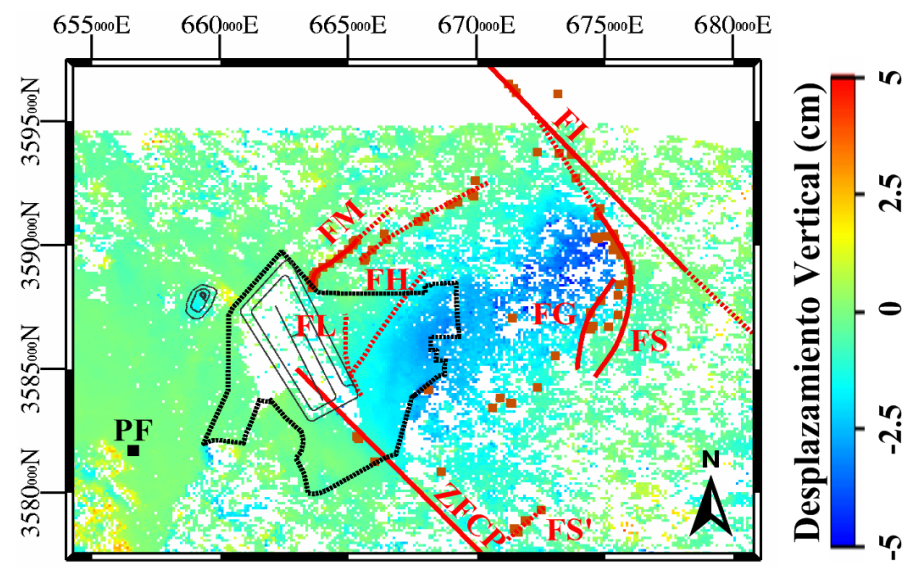

Figura 5. a y b: Imágenes de coherencia para dos pares seleccionados. c y d: Interferogramas diferenciales de fase enrollada filtrada usando filtro de Goldstein. e y f: Desplazamiento vertical absoluto. Se aplicó la máscara para los pixeles con coherencia $<0.1$ en c-f. Anotaciones como en la Figura 2. 


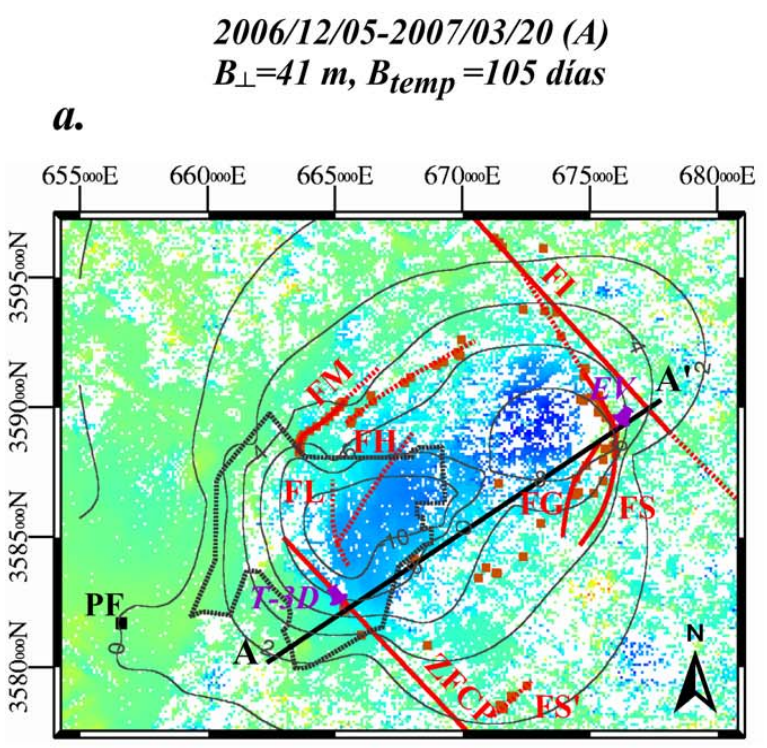

c.

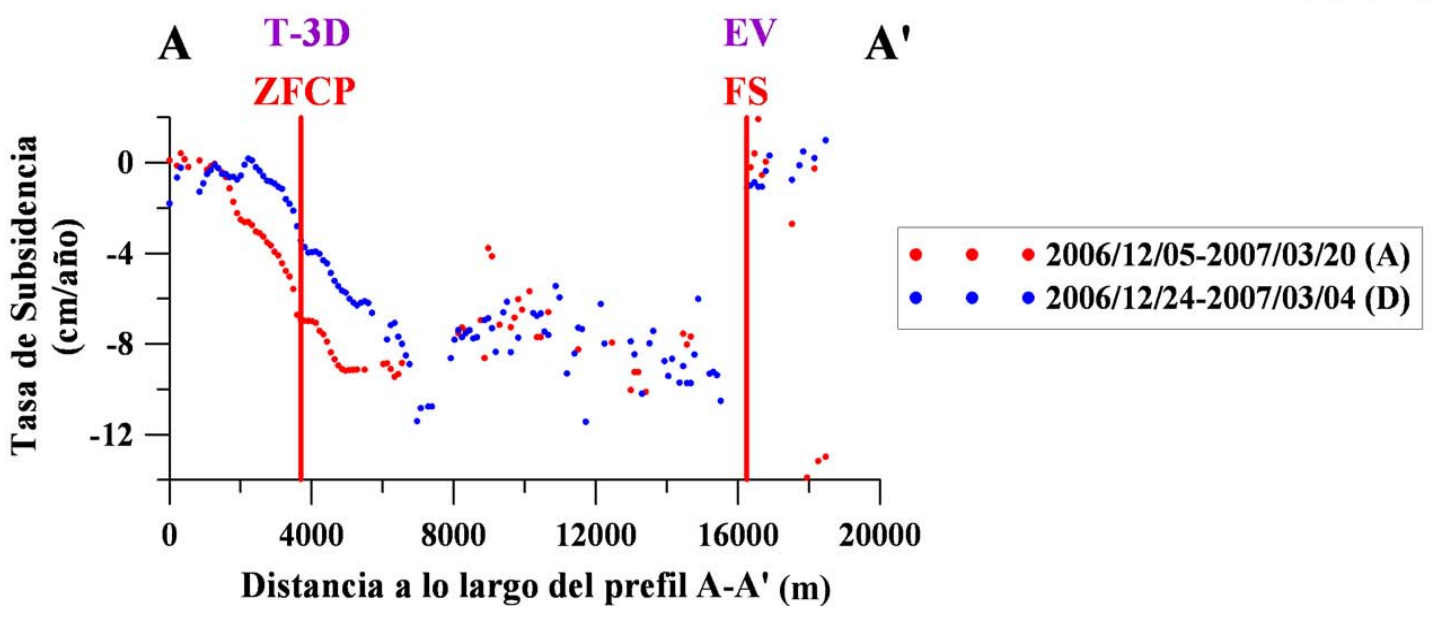

Figura 6. a y b. Mapas de tasa de subsidencia ( $\mathrm{cm} / \mathrm{año}$ ) obtenida de dos pares interferométricos seleccionados. Se aplicó la máscara para los pixeles con coherencia $<0.1$. Ubicación de extensómetro vertical (EV) y testigo (T-3D) se muestra. Anotaciones como en la Figura 2. c. Tasa de subsidencia (cm/ año) a lo largo del perfil AA'.

que los valores positivos de desplazamiento LOS se deben al aumento de la distancia entre el sensor y la superficie terrestre que corresponde al hundimiento del terreno, y el hundimiento del terreno se expresa habitualmente con valores negativos (Figuras 5e, 5f, 6a, 6b), se agregó un signo “-” a la ecuación (4). El desplazamiento vertical relativo ha sido convertido al desplazamiento vertical absoluto al referenciar el campo de desplazamiento vertical al "punto fijo" (PF), restándole o agregándole un valor constante, de tal manera que en el punto fijo el valor de desplazamiento sea "0". PF es un punto muy cercano a la sierra de Cucapah, fuera de los límites de la cuenca extensional Cerro Prieto (Suárez-Vidal et al., 2008), donde los datos de GPS indican " 0 " hundimiento y es utilizado como el punto de referencia para las campañas de nivelación en esta área (Glowacka et al., 2001). Los mapas de desplazamiento vertical absoluto para los pares interferométricos escogidos se presentan en la Figura 5e y $5 \mathrm{f}$. Los valores negativos indican la subsidencia del terreno.

A partir de los mapas de desplazamiento vertical absoluto se obtuvieron los mapas de tasa de subsidencia anual (Figura 6a y 6b), para poder realizar la comparación directa entre resultados obtenidos de pares interferométricos escogidos, que cubren diferentes periodos de tiempo, y posteriormente compararlos con los datos de nivelación de 1994-1997.

Las diferencias en la tasa y el patrón del hundimiento entre estos dos mapas (Figura 6a y $6 \mathrm{~b}$ ) pueden estar causadas por errores de desenrollo de la fase, presencia de los efectos atmosféricos locales, presencia del desplazamiento horizontal y diferencia en intervalos de tiempo que cubren los pares interferométricos escogidos (105 y 70 días). En 
ambos mapas se observa el hundimiento al noreste de la laguna de evaporación, en forma de " 8 ", con un máximo hundimiento del orden de $18 \mathrm{~cm} /$ año situado entre el límite este del campo geotérmico Cerro Prieto y la falla Saltillo, y otro, con la tasa de hundimiento del orden de $14-16 \mathrm{~cm} /$ año, observado en la parte este del campo geotérmico Cerro Prieto, en la nueva zona de producción-CPIV (Figura 2). La extensión de la zona de hundimiento es hacia el noreste, perpendicular a las fallas principales. La zona de hundimiento está limitada por la falla Saltillo al noreste y este, y la zona de falla Cerro Prieto al oeste.

En la Figura 6c se presenta la velocidad de desplazamiento LOS (cm/año) a lo largo del perfil AA' que cruza ambas fallas mencionadas en los puntos donde se encuentran trabajando los instrumentos geotécnicos. En la Figura $6 \mathrm{c}$ se observa una fuerte diferencia de gradiente de desplazamiento en la falla Saltillo y zona de falla Cerro Prieto. El desplazamiento a lo largo de la falla Saltillo es mucho más intenso que en la zona de falla Cerro Prieto, lo que está de acuerdo con las mediciones hechas en las fallas con extensómetro vertical y testigo 3D. Los datos de DInSAR repor$\tan 7.5-9.4 \mathrm{~cm} /$ año de desplazamiento vertical relativo en la falla Saltillo y $2.2 \mathrm{~cm} /$ año en la falla Cerro Prieto. Estos valores están en acuerdo con la tasa de desplazamiento vertical reportado por los instrumentos geotécnicos: EV reporta $7.3 \mathrm{~cm} /$ año y testigo $3 \mathrm{D}$ reporta $3.1 \mathrm{~cm} /$ año, en la falla Saltillo y Cerro Prieto, respectivamente.

La discrepancia entre la tasa de desplazamiento vertical reportada por dos técnicas, DInSAR e instrumentación geotécnica, se debe, principalmente, a las diferencias en la resolución espacial. La instrumentación geotécnica es un método de medición puntual; los instrumentos reportan el desplazamiento vertical relativo ocurrido en la distancia de $\sim 3 \mathrm{~m}$. La resolución espacial máxima para la técnica de DInSAR está limitada por el tamaño de pixel $(\sim 100 \times 100$ $\left.\mathrm{m}^{2}\right)$. La ausencia de pixeles con buena coherencia $(>0.1)$ en la zona cercana a las fallas (Figura 6c) degrada la resolución espacial del método de DInSAR; el desplazamiento relativo en la distancia de hasta $\sim 1000 \mathrm{~m}$ fue tomado en cuenta. Adicionalmente, la estructura compleja de la zona de las fallas puede influir en los resultados.

Como no se observa hundimiento significativo al noroeste de la falla Morelia y la zona de fisuras que continúa en dirección de la falla Imperial (Figura 5c-5f y Figura 6a y 6b), se puede sugerir que éstos constituyen el límite noroeste del área afectada por subsidencia. El mismo argumento puede ser usado en caso del límite suroeste de la zona de hundimiento donde no se observa hundimiento al suroeste de la zona de fracturas, considerada como la continuación de la falla Saltillo, FS' (Suárez-Vidal et al., 2008).

Aquí cabe mencionar que ningún par interferométrico reporta el hundimiento relacionado con la estructura del Graben Guerrero (Figura 6).

En la Figura 6a y 6b, también se comparan los resultados de esta publicación con los resultados de nivelación para los años 1994-1997 (Glowacka et al., 1999, 2005). Para eso, sobrepusimos los datos de nivelación 1994-1997 (en forma de isolíneas) a los mapas de tasa de subsidencia obtenidos usando la técnica de DInSAR (Figura 6a y 6b). Se puede notar en la Figura 6a y $6 \mathrm{~b}$ que la tasa de subsidencia aumentó en toda la zona del centro de dispersión. El mayor aumento, de $9 \mathrm{~cm} /$ año a $18 \mathrm{~cm} /$ año, se observa en la parte noreste del área de estudio, fuera del campo geotérmico, en la zona reconocida como zona de recarga (Glowacka et al., 1999, 2002). Dentro del campo geotérmico, la tasa de subsidencia aumentó de $12 \mathrm{~cm} /$ año para los años 94-97, hasta 14-16 cm/año para los años 2006-2007, y la zona con el máximo hundimiento migró en la dirección noreste. El aumento en la tasa de subsidencia puede estar relacionado con un aumento en el volumen extraído, el cual se incrementó $\sim 18 \%$ para el año 2006 (CFE, 2006), comparando con el volumen de extracción en los años 1994-1997. La migración del máximo de hundimiento fue observado anteriormente por Sarychikhina et al. (2007) y diagnosticado como efecto del inicio de extracción en la zona CPIV. El mismo cambio en producción cambió la posición de la zona de máximo hundimiento en el área de pozos.

\section{Conclusiones}

Se aplicó la técnica de DInSAR para el monitoreo del hundimiento en el Valle de Mexicali. Los resultados obtenidos con pares interferométricos ascendente y descendente, de línea de base perpendicular de decenas de metros y cubrimiento temporal de 105 días (2006/12/05-2007/03/20) y 70 días (2006/12/24-2007/03/04), respectivamente, tomados en la temporada de invierno, muestran buena coherencia $(>0.1)$ sobre casi toda la zona analizada.

El análisis conjunto de datos de DinSAR, instrumentos geotécnicos y datos de levantamiento geotectónico proporciona información acerca de los límites de la zona afectada por subsidencia. Estos límites están bien relacionados con las trazas de falla tectónicas conocidas y las zonas de fracturas.

La comparación de los DInSAR 2006-2007 y los datos de nivelación 1994-1997 aporta información importante acerca de la dinámica del proceso de hundimiento que se relaciona con el desarrollo de producción en el campo geotérmico Cerro Prieto.

En este trabajo, para los datos de DInSAR se incluyó solamente el análisis de pares interferométricos individuales, para el cual se escogieron dos pares interferométricos con los mejores parámetros y el menor nivel de ruido (según el análisis visual). Sin embargo, es factible mejorar la calidad, la resolución espacial y el cubrimiento temporal de los datos de DInSAR aplicando los métodos avanzados de DInSAR, tales como apilamiento de múltiples interferogramas (stacking) o PSInSAR (Permanent/Persistent Scatterers InSAR); esto se propone realizar como continuación de este trabajo. 


\section{Agradecimientos}

Este trabajo fue posible gracias al apoyo económico de CONACYT (45997-F), y CONAGUA, OCPBC. O.S. agradece la beca de la Secretaría de Relaciones Exteriores. Las imágenes de ENVISAT fueron obtenidos de ESA por medio del proyecto C1P3508.

Los autores agradecen a los árbitros revisores, Enrique Cabral Cano y Pablo Blanco Sánchez, por las sugerencias y comentarios que permitieron reanalizar los datos y el manuscrito de manera más crítica.

\section{Bibliografía}

Amelung, F., Jónsson, S., Zebker, H., Segall, P., 2000, Widespread uplift and 'trapdoor' faulting on Galápagos volcanoes observed with radar interferometry: Nature, 407, 993-996.

Bawden, G. W., Thatcher, W., Stein, R. S., Hudnut, K. W., Peltzer, G., 2001, Tectonic contraction across Los Angeles after removal of groundwater pumping effects: Nature, 412, 812-815.

Carnec, C., Massonnet, D., King, C., 1996, Two examples of the use of SAR interferometry on displacement fields of small spatial extent: Geophysical Research Letters, 23, 3579-3582.

Carnec, C., Fabriol, H., 1999, Monitoring and modeling land subsidence at the Cerro Prieto geothermal field, Baja California, Mexico, using SAR interferometry: Geophysical Research Letters, 26 (9), 1211-1214.

Carnec, C., Delacourt, C., 2000, Three years of mining subsidence monitored by SAR interferometry, near Gardanne, France: Journal of Applied Geophysics, 43, 43-54.

Comisión Federal de Electricidad (CFE), 2006, Cerro Prieto Geothermal Field: Residencia General de Cerro Prieto, Baja California, México, Comisión Federal de Electricidad, 36 p.

Chen, C.W., Zebker, H.A., 2000, Network approaches to two-dimensional phase unwrapping: intractability and two new algorithms: Journal Optical Society of America, 17, 401-414.

Chen, C.W., Zebker, H.A., 2001, Two-dimensional phase unwrapping with use of statistical models for cost functions in nonlinear optimization: Journal Optical Society of America, 18, 338-351.

Fabriol, H., Munguía, L., 1997, Seismic activity at the Cerro Prieto geothermal area (México) from August 1994 to December 1995, and its relationship with tectonics and fluid exploitation: Geophysical Research Letters, 24, 1807-1810.

Fialko, Y., Simons, M., 2000, Deformation and seismicity in the Coso geothermal area, Inyo Country, California: Observations and modeling using satellite radar interferometry: Journal of Geophysical Research, 105, 21,781-21,793.

Fielding, E.J., Talebian, M., Rosen, P.A., Nazari, H., Jackson, J.A., Ghorashi, M., Berberian, M., 2005, Surface ruptures and building damage of the 2003 Bam, Iran earthquake mapped by satellite synthetic aperture radar interferometric correlation: Journal of Geophysical Research, 110 (B3), B03302 p. doi:10.1029/2004JB003299.

Glowacka, E., 1996, Vertical Creepment in the Southern Part of Imperial Fault (México), (resumen), in AGU Fall Meeting: San Francisco, California, EUA, American Geophysical Union, Proceedings, F516.

Glowacka, E., 1999, Deformaciones Superficiales en el Área de Cerro Prieto, B. C., México, y sus Relaciones con Sismicidad, Tectónica Local y Extracción de Fluidos: Geotermia, Revista Mexicana de Geoenergía, 15, 39-46.

Glowacka, E., Nava, F.A., 1996, Major Earthquakes in Mexicali Valley, México, and Fluid Extraction at Cerro Prieto Geothermal Field: Bulletin of the Seismological Society of America, 86, 93-105.

Glowacka, E., González, J., Fabriol, H., 1999, Recent Vertical deformation in Mexicali Valley and its Relationship with Tectonics, Seismicity and Fluid Operation in the Cerro Prieto Geothermal Field:
Pure and Applied Geophysics, 156, 591-614.

Glowacka, E., González, J.J., Nava, F.A., Farfan, F., Diaz de Cossio, G., 2001, Monitoring Surface Deformations in the Mexicali Valley, B.C., México (resumen), in 10th International Symposium on Deformation Measurements: Orange, California, USA, FIG (International Federation of Surveyors), 175-183.

Glowacka E., Nava, F.A., Díaz de Cossío, G., Wong, V., Farfán, F., 2002, Fault slip, Seismicity and Deformation in Mexicali Valley (Baja California, Mexico) after the M7.1 1999 Hector Mine Earthquake: Bulletin of the Seismological Society of America, 92, 1290-1299.

Glowacka, E., Sarychikhina, O., Nava, F.A., 2005, Subsidence and stress change in the Cerro Prieto Geothermal Field, B.C., México: Pure and Applied Geophysics, 162, 2095-2110.

Glowacka, E., Sarychikhina, O., Suárez, F., Mendoza, R., Nava, F.A., 2006, Estudio geológico para definir la zona de hundimiento con el fin de relocalización del canal Nuevo Delta en el Valle de Mexicali: Baja California, México, CICESE, reporte técnico, 513 p.

Glowacka, E., Sarychikhina, O., Suárez, F., Nava, F.A., Mellors, R., 2010, Anthropogenic subsidence in the Mexicali Valley, Baja California, México, and slip on the Saltillo fault: Environmental Earth Sciences, 59, 1515-1524.

Goldstein, R.M., Engelhardt, H., Kamb, B., Frolich, R.M., 1993, Satellite radar interferometry for monitoring ice sheet motion: application to an Antarctic ice stream: Science, 262, 1525-1530.

Goldstein, R.M., Werner, C.L., 1998, Radar interferogram filtering for geophysical applications: Geophysical Research Letters, 25, 40354038.

González, J., Glowacka, E., Suárez, F., Quiñones, J.G., Guzmán, M., Castro, J.M., Rivera, F., Félix, M.G., 1998, Movimiento reciente de la Falla Imperial, Mexicali, B.C.: Ciencia para todos Divulgare, 22, 4-15.

Hanssen, R., 2001, Radar Interferometry: Data Interpretation and Error Analysis: Dordrecht, Holland, Kluwer Academic Publishers, 308 p.

Henderson, F.M., Lewis, A.J. (eds.), 1998, Manual of remote sensing. Volume 2. Principles and Applications of Imaging Radar. New York, USA. John Wiley and Sons, Inc. 896 p.

Hoffmann, J., Zebker, H.A., Galloway, D.L., Amelung, F., 2001, Seasonal subsidence and rebound in Las Vegas Valley, Nevada observed by synthetic aperture radar interferometry: Water Resources Research, $37,1551-1566$.

Kampes, B, 2005, Delft Object-oriented Radar Interferometric Software User's manual and technical documentation (en línea): The Netherlands, Delft University of Technology, actualizado 01 de septiembre de 2010, disponible en http://doris.tudelft.nl/>, consultado $1 \mathrm{de}$ septiembre de 2006

Kampes, B., Usai, S., 1999, Doris: the delft object-oriented radar interferometric software, in Proceedings of Second International Symposium on Operationalization of Remote Sensing: Enschede, The Netherlands, disponible en http://citeseerx.ist.psu.edu/viewdoc/do wnload?doi=10.1.1.46.1689\&rep=reps\&type $=$ pdf, consultado 30 de agosto de 2006 .

Kampes, B., Hanssen, R., Perski, Z., 2003, Radar interferometry with public domain tools, in Proceedings of FRINGE 2003: Frascati, Italy, actualizado el 01 de septiembre de 2010, disponible en <http:// doris.tudelft.nl/>, consultado 1 de septiembre de 2006 .

Kwok, R., Fahnestock, M.A., 1996, Ice sheet motion and topography from radar Interferometry: IEEE Transactions on Geoscience and Remote Sensing, 34, 189-200.

Lira-Herrera, 2006, Características del sismo del 23 de Mayo de 2006: México, Comisión Federal de Electricidad, Residencia de Estudios. Informe RE-023/2006

Lomnitz C., Moosser, F., Allen, C.R., Brune, J.N., Thatcher, W., 1970, Seismicity and tectonics of the northern Gulf of California region, Mexico, preliminary results: Geofísica Internacional, 10, 37-48.

Majer, E.L., McEvilly, T.V., 1982, Seismological studies at the Cerro Prieto Geothermal Field, 1978-1982 (resumen), in Proceedings Fourth Symposium on the Cerro Prieto Geothermal Field: Guadalajara, Mexico, Comisión Federal de Electricidad, 145-151. 
Massonnet, D., Rossi, M., Carmona, C., Adragna, F., Peltzer, G., Feigl, K., Rabaute, T., 1993, The displacement field of the Landers earthquake mapped by radar interferometry: Nature, 364, 138-142.

Massonnet, D., Briole, P., Arnaud, A., 1995, Deflation of Mount Etna monitored by spaceborne radar interferometry: Nature, 375, 567-570.

Massonnet, D., Holzer, T., Vadon, H., 1997, Land subsidence caused by the East Mesa geothermal field, California, observed using SAR interferometry: Geophysical Research Letters, 24, 901-904.

Muller, J. P., Backes, D., 2003, Quality assessment of X-and C-SRTM with ERS-tandem DEMs over 4 European CEOS WGCV test sites (resumen), in Proceedings of FRINGE 2003: Frascati, Italy, European Space Agency.

Nava, F. A., Glowacka, E., 1999, Fault-slip Triggering, Healing, and Viscoelastic Afterworking in Sediments in the Mexicali-Imperial Valley: Pure and Applied Geophysics, 156, 615-629.

Sarychikhina, O., 2003, Modelación de subsidencia en el campo geotérmico Cerro Prieto: Baja California, México, CICESE, tesis de maestría, $101 \mathrm{p}$.

Sarychikhina, O., Glowacka, E., Mellors, R., 2007, Preliminary results of a surface deformation study, using differential InSAR technique at the Cerro Prieto Geothermal Field, B.C., México: Geothermal Resources Council Transactions, 31, 581-584.

Sarychikhina, O., Glowacka, E., Mellors, R., Vázquez, R., Munguía, L., Guzmán, M., 2009. Surface Displacement and Groundwater Level Changes Associated with the 24 May 2006 Mw 5.4 Morelia Fault
Earthquake, Mexicali Valley, Baja California, México: Bulletin of the Seismological Society of America, 99, 2180-2189.

Sigmundsson,F., Durand, P., Massonnet, D., 1999, Opening of an eruptive fissure and seaward displacement at Piton de la Fournaise volcano measured by RADARSAT satellite radar interferometry: Geophysical Research Letters, 26, 533-36.

Stramondo, S., Tesauro, M., Briole, P., Sansosti, E., Salvi, S., Lanari, R., Anzidei, M., Baldi, P., Fornaro, G., Avallone, A., Buongiorno, M.F., Franceschetti, G., Boschi, E., 1999, The September 26, 1997 Colfiorito, Italy, earthquakes: modeled coseismic surface displacement from SAR Interferometry and GPS: Geophysical Research Letters, 26, 883-886.

Suárez-Vidal, F., Munguía-Orozco, L., González-Escobar, M., GonzálezGarcía, J., Glowacka, E., 2007, Surface Rupture of the Morelia Fault Near the Cerro Prieto Geothermal Field, Mexicali, Baja California, México, during the Mw 5.4 Earthquake of 24 May 2006: Seismological Research Letters, 78, 394-399.

Suárez-Vidal, F, Mendoza-Borunda, R., Naffarrete-Zamarripa, L.M., Ramírez-Hernández, J., Glowacka, E., 2008, Shape and dimensions of the Cerro Prieto pull-apart basin, Mexicali, Baja California, Mexico, based on the regional seismic record and surface structures: International Geology Review, 50, 636-649.

Wegmüller, U., Werner, C., Strozzi, T., Wiesmann, A., 2004, Monitoring mining induced surface deformation: IGARSS04 Proceedings, Anchorage, Alaska, USA, 3, 1933-1935.

Recibido: 23/09/2009

Recibido corregido: 18/09/2010

Aceptado: 26/10/2010 